\title{
Pathogenic Tau Protein Species: Promising Therapeutic Targets for Ocular Neurodegenerative Diseases
}

\author{
Mohammad Amir Mishan ${ }^{1}$, MS; Mozhgan Rezaei Kanavi², MD; Koorosh Shahpasand ${ }^{3}$, PhD; Hamid Ahmadieh ${ }^{4}$, \\ MD \\ ${ }^{1}$ Ocular Tissue Engineering Research Center, Student Research Committee, Shahid Beheshti University of Medical Sciences, \\ Tehran, Iran \\ ${ }^{2}$ Ocular Tissue Engineering Research Center, Shahid Beheshti University of Medical Sciences, Tehran, Iran \\ ${ }^{3}$ Department of Brain and Cognitive Sciences, Cell Science Research Center, Royan Institute for Stem Cell Biology and \\ Technology, ACECR, Tehran, Iran \\ ${ }^{4}$ Ophthalmic Research Center, Shahid Beheshti University of Medical Sciences, Tehran, Iran
}

ORCID:

Mohammad Amir Mishan: https://orcid.org/0000-0001-8210-9322

Mozhgan Rezaei Kanavi: https://orcid.org/0000-0002-1497-2260

\begin{abstract}
Tau is a microtubule-associated protein, which is highly expressed in the central nervous system as well as ocular neurons and stabilizes microtubule structure. It is a phospho-protein being moderately phosphorylated under physiological conditions but its abnormal hyperphosphorylation or some postphosphorylation modifications would result in a pathogenic condition, microtubule dissociation, and aggregation. The aggregates can induce neuroinflammation and trigger some pathogenic cascades, leading to neurodegeneration. Taking these together, targeting pathogenic tau employing tau immunotherapy may be a promising therapeutic strategy in fighting with cerebral and ocular neurodegenerative disorders.
\end{abstract}

Keywords: Microtubule-associated Protein; Neurodegenerative Disorders; Tau; Ocular Neurons

J Ophthalmic Vis Res 2019; 14 (4): 491-505

\section{Correspondence to:}

Mozhgan Rezaei Kanavi, MD. Ocular Tissue Engineering Research Center, Shahid Beheshti University of Medical Sciences, No. 23, Paidarfard St., Boostan 9 St., Pasdaran Ave., Tehran 16666, Iran.

E-mail: mrezaie47@yahoo.com

Received: 07-12-2018Ａccepted: 11-06-2019

\section{Access this article online}

Website:

https://knepublishing.com/index.php/JOVR

DOI:

10.18502/jovr.v14i4.5459

\section{INTRODUCTION}

Tau is a microtubule (MT)-associated protein and the most common unfolded protein upon neurodegenerative disorders, which was described in 1975 by Weingarten and colleagues. ${ }^{[1]}$ This protein gene encoding (MAPT), being located at chromosome 17q21, ${ }^{[2]}$ is predominantly expressed in various regions of the human brain, mostly in neurons and to a lesser degree in astrocytes and oligodendrocytes. ${ }^{[3,4]}$ Tau is an axonal protein, binds to MTs by its MT-binding domain, stabilizing microtubule structure and the cytoskeleton. ${ }^{[5-7]}$ Other functions of tau are their roles in cargo conveyance and signaling pathways. ${ }^{[8,9]}$ Tau aggregation is widely accepted as a pathological process in central nervous system (CNS), leading to

This is an open access journal, and articles are distributed under the terms of the Creative Commons Attribution-NonCommercial-ShareAlike 4.0 License, which allows others to remix, tweak, and build upon the work non-commercially, as long as appropriate credit is given and the new creations are licensed under the identical terms.

How to cite this article: Mishan MA, Kanavi MR, Shahpasand K, Ahmadieh H. Pathogenic Tau Protein Species. J Ophthalmic Vis Res 2019;14:491-505. 
neurodegenerative disorders such as: Alzheimer disease $(A D)$ and post-traumatic brain injuries ${ }^{[10]}$. Since ocular neurodegeneration is similar to CNS neurodegenerative disorders, there are several evidences that pathogenic forms of tau are prone to aggregation and responsible for retinal degeneration in the subjects with ocular neurodegeneration, such as age-related macular degeneration (AMD) and glaucoma. ${ }^{[1-13]}$ With this in mind, we aimed to summarize scientific reports focusing on the role of tauopathy in the pathogenesis of neurodegenerative diseases, in particular in the eye, and to explain the role of targeted therapy as a promising therapeutic modality for pathogenic tau aggregations.

\section{Tau Gene}

The MAPT gene include 16 exons, of which 11 are expressed in the human brain and 6 main isoforms of $37-46 \mathrm{kDa}$ tau mRNA are produced by alternative splicing that results in production of six tau protein isoforms. Difference between the isoforms is dependent on the $\mathrm{N}$-terminal region where the number of copies of a repeated motif consisting of 29 -amino acids $(0 \mathrm{~N}, 1 \mathrm{~N}$, or $2 \mathrm{~N})$, and the C-terminus including either three (3R tau) or four (4R tau) MT-binding repeats. ${ }^{[14-16]}$ In human CNS, the longest tau isoform with 441 amino acids, 2N4R, has $80 \mathrm{Thr}$ and Ser residues that can be modified by numerous kinases ${ }^{[18]}$ and a low proportion of hydrophobic amino acids, which renders tau a hydrophilic protein. ${ }^{[17]}$

Differential splicing that alters tau protein isoform expression occurs at every step of development and neuronal maturation. ${ }^{[10]}$ In the adult brain, all six tau isoforms are expressed, in contrast to fetal brain where the shortest tau isoform (ON3R) is expressed. ${ }^{[16]}$ In the cerebral cortex of healthy adults, approximately equal amounts of $3 R$ and $4 R$ tau isoforms are expressed. ${ }^{[16]}$ Additionally, it has been reported that there is 3R/4R ratio changes in the $A D$ patient brains compared to the healthy subjects, demonstrating that the isoforms ratio is a determinant factor in tau pathogenicity and aggregation.

Regional splicing of tau mRNA has also been observed in human brain. The expression rate of ON3R tau isoform in the cerebellum is lower than other regions in human brain and $4 \mathrm{R}$ tau isoforms are highly expressed in the globus pallidus. ${ }^{[19,20]}$

\section{Tau Protein Structure}

Tau protein has a flexible conformation with a low level of secondary structure ${ }^{[21,22]}$ and is subdivided into four domains with different biochemical properties. The $\mathrm{N}$-terminal acidic domain with 1150 amino acids includes two N-terminal inserts. Tau protein amino acids 151-243 are known as the proline-rich domain. ${ }^{[6]}$ The MT-binding domain of tau consists of four repeated motifs that are separated from each other by flanking regions, which altogether provide a structure by which the tau can bind to and stabilize MTs. ${ }^{[22,23]}$ Amino acids 370-441 are known as the C-terminal region. ${ }^{[22]}$

The N-terminal domain protrudes out of the MT surface, and although this domain does not bind directly to MTs, it has a role in MT assembly regulation and affects the attachment or spacing between MTs and other components in the cell. ${ }^{[24]}$ The N-terminal inserts affect the distribution of tau molecules in the cell; it was demonstrated that each tau isoform $(0 \mathrm{~N}, 1 \mathrm{~N}$, and $2 \mathrm{~N})$ has different subcellular localizations in the mouse brain. ${ }^{[25]}$ In addition, tau, via interacting with the membrane binding protein annexin $A 2$, interacts with the plasma membrane by its $\mathrm{N}$-terminal domain. ${ }^{[26,27]}$ The $\mathrm{N}$-terminal domain can also bind to the $\mathrm{C}$ terminus of p150 in dynactin protein, which has an essential role in the connection between dynein and cargoes. ${ }^{[28]}$ Moreover, tau isoforms have distinct protein interaction patterns; for instance, apolipoprotein $\mathrm{A} 1$ can bind to $2 \mathrm{~N}$ tau isoforms; however, synaptophysin and $\beta$-synuclein attach to ON tau isoforms. ${ }^{[29]}$

The proline-rich domain of tau has several recognition sites for attaching Src homology-3 (SH3)-containing proteins such as the Src family of protein kinases (LCk, Fgr, and Fyn), the p85 $\alpha$ regulatory subunit of phosphatidylinositol 3-kinase (PI3K), bridging integrator 1 (Bin1), phospholipase C (PLC), Y1, PLC Y2, growth factor receptor bound protein 2, and peptidylprolyl cis/trans isomerases NIMA-interacting 1. ${ }^{[30]}$ Tau interactions with $\mathrm{SH}$ containing proteins play an important role in modulating the signaling functions of tau. Additionally, signaling pathways are associated with the activation of phosphatidylinositol and phosphatidylinositol bisphosphate, which collaborate with the tau proline-rich domain. ${ }^{[31,32]}$ Furthermore, the tau proline-rich domain acts as a DNA and RNA recognition site. ${ }^{[33,34]}$ This domain also has an 
important role in the inter MT spacing and intracellular trafficking ${ }^{[35,36]}$ as well as actin binding, ${ }^{[37]}$ highlighting an important role in neuronal cell signaling and neuronal plasticity.

\section{Tau Post-translational Modifications}

Although several post-translational modifications, in forms of phosphorylation, acetylation, glycation, cleavage or truncation, prolyl-isomerization, polyamination, nitration, ubiquitination, oxidation, and sumoylation have been identified to modulate tau protein, ${ }^{[38-40]}$ the most well-known is phosphorylation in which the abnormal hyperphosphorylation is associated with tauopathy. ${ }^{[41]}$ Although phosphorylation is an essential tau modifier under physiological conditions, ${ }^{[1]}$ abnormal phosphorylation or hyperphosphorylation are other modifiers by which tau gets prone to aggregation. ${ }^{[42,43]}$ For instance, hyperphosphorylated tau forms the oligomers and neurofibrillary tangles (NFTs) that exert toxic effects on neuronal function and $A D$ progression. $^{[44]}$

Although 15-30 phosphorylation sites, that mostly corresponded to proline-directed sites in the proline-rich domain of tau were discovered in tau protein, ${ }^{[45]}$ increased phosphorylation, especially at the MT-binding domains, has also been demonstrated in association with increased MT dynamicity and reduced levels of neuronal excitability in the early stages of $A D{ }^{[46]}$

Threonine ${ }^{175}\left(\mathrm{Thr}^{175}\right)$ is one of the important phosphorylation sites in tau protein that was first identified in $A D^{[47]}$ and then in amyotrophic lateral sclerosis (ALS) with cognitive impairment (ALSci). ${ }^{[48-52]}$ This modification site can be phosphorylated by multiple kinases related to tauopathy, including GSK3 $\beta$, JNK, ERK2, and p38, ${ }^{[53]}$ that induce tau aggregation. ${ }^{[54]}$ pThr ${ }^{175}$ tau induces GSK3 $\beta$ activation and can augment tau phosphorylation at $\mathrm{Thr}^{231}$ and other residues. This results in dissociation of tau from MTs, self-aggregation, and neuronal toxicity. ${ }^{[55]}$

Threonine ${ }^{231}\left(\mathrm{Thr}^{231}\right)$ is another important phosphorylation site in tau protein that is phosphorylated or hyperphosphorylated in the cerebrospinal fluid of $A D$ patients, and is correlated with memory loss and progression of $A D$ from mild to severe cognitive impairments. ${ }^{[56]}$

Tau hyperphosphorylation may result from downregulation of phosphatases, especially protein phosphatase $2 \mathrm{~A}$ by okadaic acid $(\mathrm{OA}){ }^{[57]}$ It was shown that OA treatment induced phosphorylation of tau at $\mathrm{Ser}^{202}$ and $\mathrm{Ser}^{396}$ in cultivated neuroblastoma cells. ${ }^{[58]}$

Cystatin $\mathrm{C}$ (CysC) is a cysteine protease inhibitor of cathepsin family, lysosomal proteases, that is widely expressed in various cells and tissues. ${ }^{[59]}$ CysC protein and its gene are upregulated in $A D$ brains, posing a risk factor for late-onset $A D{ }^{[60,61]}$ CysC does not affect production of cellular amyloid beta peptide $(A \beta)$; however, overexpression of Cys $C$ in neurons leads to inhibition of GSK3 $\beta$ turnover, augmentation of GSK3 $\beta$ levels in neurons that promotes GSK3 $\beta$ tau phosphorylation at Ser ${ }^{396 / 404}$, MT instability, and neurodegeneration. ${ }^{[62,63]}$

GSK3 $\beta$ is one of the kinases having an important role in NFT formation and dystrophic neurites by tau phosphorylation in the brain. ${ }^{[64-67]}$ High activity of GSK3 $\beta$ can be detected in the frontal cortex ${ }^{[68]}$ and hippocampus of AD patients. ${ }^{[65]}$ It is notable that Lithium, as a potent GSK3 $\beta$ inhibitor, is being widely prescribed for neurodegenerative disorders such as AD.

Cyclin-dependent kinase 5 (Cdk5) is a prolinedirected Ser/Thre kinase, that can phosphorylate tau at several Ser-Pro and Thre-Pro motifs. Phosphorylation at these residues affects MT stability via dissociation of tau from MTs. Cdk5 is highly expressed in axons and growth cones serving to induce neurite outgrowth and cell migration. ${ }^{[69]}$

Peptidyl-prolyl cis-trans isomerase NIMAinteracting 1 (Pin1), a phospho-Ser/Thr isomerase with a regulatory role on tau function, is known to be a critical factor playing part in the $A D$ development. Pin1 converts cis to trans p-tau whereby preventing pathogenic cis $\mathrm{p}^{231}$-tau accumulation (cistauosis) and maintaining tau in a trans conformation. ${ }^{[70]}$

\section{Tau Aggregation}

Insoluble tau deposits, resulting from tau misfolding and oligomerization, gradually accumulate in neurons, disrupt cell function, and initiate neurodegeneration. ${ }^{[71]}$ Two hexapeptide repeats, amino acids 306-311 (PHF6, Val-GIn-lle-Val-LysTyr, VQIVKY) and 317-335 (PHF6*, Val-GIn-lle-lleLys-Tyr VQIINK), in the C-terminal region of tau protein play a significant role in the formation of $\beta$ sheets and fibrillary tangles. ${ }^{[6,72,73]}$ PHF6, located 
at the beginning of the third MT-binding repeat, is present in all tau isoforms, but PHF6* is located at the beginning of the second MT-binding repeat. It was observed that PHF6 and PHF6* can attach to each other and form tau fibrillary tangles. ${ }^{[7]}$ Tau dimerization can occur by interaction between two PHF6, two PHF6*, or between one PHF6 and one PHF6* motif. ${ }^{[75]}$ Finally, tau oligomers elongate and form cross $\beta$-sheet structures, forming the aggregates. ${ }^{[76]}$ Although PHF6 and PHF6* are prone to self-assembly, native tau under physiological conditions is resistant to aggregation. Factors enhancing the self-assembly of tau or neutralizing its charge can induce tau aggregation. Due to the presence of PHF6* encoded by exon 10, 4R tau isoforms are more prone to aggregation than $3 R$ tau isoforms. ${ }^{[77,78]}$ Mutations within the hexapeptide motifs, such as the P301L tau mutation, promote tau aggregation in patients with frontotemporal dementia and parkinsonism linked to chromosome 17 (FTDP-17). ${ }^{[79]}$ In addition to the tendency of exon 10 for aggregation, the $\mathrm{N}$-terminal insert encoded by exon 2 induces tau self-aggregation, whereas the expression of exon 3 has an inhibitory role on aggregation via a process modulated by the expression of exon 10. ${ }^{[80]}$ Also, deletion of the positively charged Lys $(K)^{280}$ residue can suppress tau self-assembly. ${ }^{[4,80]}$

It was demonstrated that anionic condensing agents can induce tau aggregation. For instance, heparin can bind to the second and third MT-binding repeats, the flanking region, and the $\mathrm{N}$-terminal of tau protein, and induce tau aggregation. ${ }^{[81,82]}$ Fatty acids, polyglutamic acid, and tRNA, can also induce tau aggregation. ${ }^{[83]}$ It has been reported that preventing tau aggregation would rescue neurodegeneration. For example, Curcumin, a tau aggregation inhibitor, efficiently suppresses neurodegeneration in tauopathy mouse models.

\section{Pathogenic Role of Tau Protein in Neurode- generative Diseases}

In contrast to the normal physiological condition in which tau has a stable and unfolded monomeric conformation, in pathological conditions, tau is phosphorylated or hyperphosphorylated and self-aggregates, resulting in pathogenic conformations in neurodegenerative diseases, termed tauopathies. ${ }^{[7,84]}$ The roles of tau in physiological and pathological conditions in the cell are summarized in Figure 1.

Phosphorylation of tau at multiple residues is characteristic of many neurodegenerative diseases, which reduces the affinity of tau to MTs, increases tau self-assembly, ${ }^{[85,86]}$ and finally causes the formation of NFTs. ${ }^{[8,88]}$ The presence of NFTs in specific regions of the brain disrupts synaptic and neuronal communications, leads to progression of memory loss, and produces a rapid impairment of long-term potentiation with induction of toxic functions in the neurons. ${ }^{[43,89]}$

Pathogenic forms of tau may spread in a prionlike manner upon tauopathies, whose molecular mechanisms remain uncertain. ${ }^{[8,90]}$ Cell-to-cell transmission of the tau aggregates causes neuronal cell death and subsequent progression of disease. ${ }^{[91,92]}$ In $A D$, this process follows a distinct pattern along the neuronal connections from the entorhinal cortex to hippocampal areas and further on through the limbic system. ${ }^{[93]}$ In other tauopathies, this process appears less hierarchical throughout the brain. ${ }^{[93]}$ Moreover, the localization of tau inclusions is widely different in various neurodegenerative diseases. ${ }^{\text {[42, 94-96] }}$

In addition to $A D,{ }^{[7]}$ tau aggregates were detected in a wide range of neurodegenerative diseases including progressive supranuclear palsy (PSP), corticobasal dementia, argyrophilic grain disease, Pick disease, Huntington disease, FTDP-17, ALS, and Parkinson's disease with dementia. ${ }^{[97,98]}$ Unlike $A D$ that has $A \beta$ depositions in addition to tauopathy, PSP is a relatively pure tauopathy in which only tau deposits are seen. PSP was shown to have shared polygenic heritability with Parkinson's disease and ALS, and most of the corresponding genes were clustered around chromosome $17 .^{[99,100]}$ Interestingly, AD, primary age related tauopathy (PART), and aging-related tau astrogliopathy (ARTAG) are the predominant sporadic tauopathies, in which oligodendrocytes serve as targets for seeding and spreading pathologic tau proteins in the white matter. ${ }^{[101]}$ Given that the human retina lacks oligodendrocytes, these cells may not be a component in the pathogenesis of tauopathies in the eye. However, considering the presence of retinal microglial cells and their role in engulfing tau oligomers and induction of inflammation, ${ }^{[102]}$ they may be involved in tau seeding in retinal neurodegenerations. 


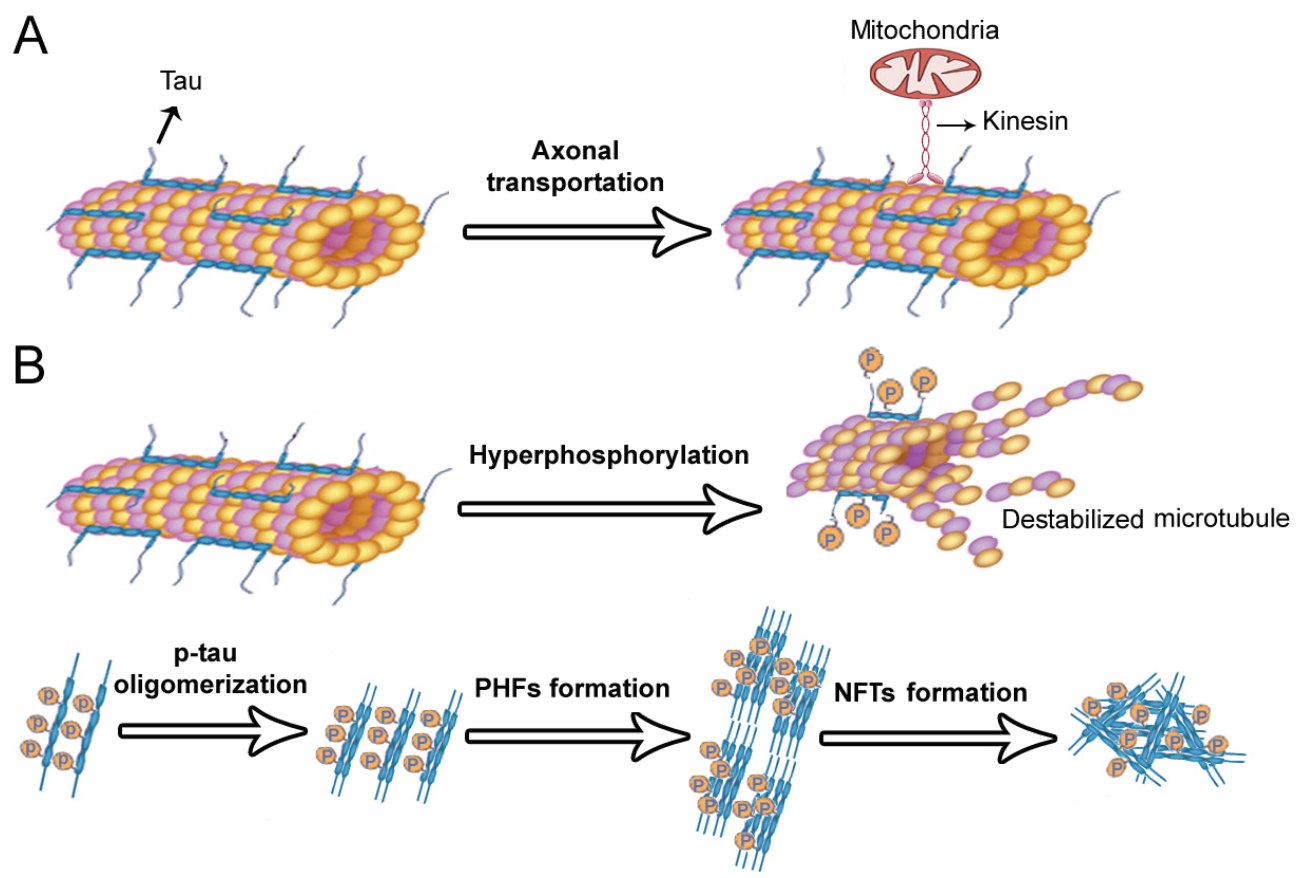

Figure 1. Tau protein. (A) In physiological conditions, tau binds to microtubules by its microtubule binding domain in order to stabilize microtubules for several cellular functions in the cells, such as axonal transportation. (B) In pathological conditions, tau is phosphorylated or hyperphosphorylated ( $p$-tau) by multiple kinases, leading to microtubule destabilization, pairing tau molecules to each other, formation of toxic oligomers, and finally NFT formation.

Tau accumulation is also a result of traumatic brain injury (TBI) and chronic traumatic encephalopathy (CTE), especially in sports that repeatedly expose athletes to mild traumatic brain injury (rmTBI) and in military personnel exposed to repeated traumas. ${ }^{[103-105]}$

Mitochondrial dysfunction and reactive oxygen species (ROS) production can induce tau hyperphosphorylation. ${ }^{[106]}$ It has been demonstrated that hyperphosphorylated tau reduces the release of cytochrome $C$ from mitochondria as well as caspase- 9 and caspase- 3 activity, and protects cells from apoptosis. ${ }^{[107]}$ Moreover, tau via stabilizing $\beta$-catenin and increasing its nuclear translocation has the ability to antagonize apoptosis and promote cell survival. ${ }^{[107,108]}$ Tau hyperphosphorylation confers cellular resistance to chemically induced apoptosis through upregulated glycogen synthase kinase-3 $\beta$ (GSK3 $\beta$ ) and preserving $\beta$ catenin. ${ }^{[108]}$

Tau overexpression causes vascular changes in the cerebral cortex that are accompanied by cortical atrophy. This overexpression in the neurons can lead to dramatic cell-nonautonomous changes in cerebral endothelial cells, alter the integrity of the cerebral microvasculature, and induce neurodegeneration related to vascular abnormalities. ${ }^{[109]}$ A similar situation occurs in AMD, where dramatic neovascular changes accompany neurodegeneration. ${ }^{[110]}$ Additionally, tau overexpression would result in impaired axonal transport, leading to neurodegeneration.

All six tau isoforms are expressed in both soluble and insoluble tau isolates in patients with CTE and CTE-ALS. The expression of oligomerized tau protein and activated GSK3 3 , pThr ${ }^{175}$ tau, and $\mathrm{pThr}^{231}$ tau were observed in hippocampal neurons and spinal motor neurons. Phosphorylation of tau at $\mathrm{Thr}^{175}$ and $\mathrm{Thr}^{231}$ and activation of GSK3 $\beta$ are reported features of tauopathy in CTE and CTEALS. ${ }^{[111]}$

A direct association has been proposed between $A \beta$ toxicity and tau pathology. ${ }^{[112,113]} \mathrm{High}$ levels of $A \beta$ in transgenic mice overexpressing amyloid precursor protein (APP) accelerated tau phosphorylation. Intracerebral injection of $A \beta$ into tau transgenic mice augmented pathogenic conditions. ${ }^{[114,115]}$ Moreover, pathogenic tau augments the secretion of $\alpha$-synuclein and induces its toxicity by promoting smaller $\alpha$-synuclein inclusion formation in human neuroglioma cells. ${ }^{[116]}$ 
It was also shown that $\alpha$-synuclein can induce tau phosphorylation. ${ }^{[117,118]}$

Cistauosis is a mechanism that occurs before insoluble tau deposition and within days after TBI. Cis p-tau is a pathogenic form of tau protein that is prominently formed in human CTE and uses a prion-like mechanism for its spreading in the brain. Inhibition of cis p-tau by monoclonal antibodies was reported to decrease cellular neurotoxicity, histopathological changes, and behavioral deficits. Cis p-tau is present in cortical axons and cerebrospinal fluid of human TBI and positively correlates with axonal injury. Therefore, antibodies that target this pathogenic form of tau are potential novel treatments for neurodegenerative diseases. $^{[70]}$

\section{Tau Isoform Pathology}

4R tau isoforms include a fourth MT-binding repeat encoded by exon 10, whereas the $3 R$ tau isoform mRNAs lacks exon 10. The majority of mutations occur in exon 10 or close by. Approximately 40 pathogenic mutations in the MAPT gene have been identified, most of them are associated with clinical signs of FTDP-17 with degeneration in the frontotemporal lobar regions. ${ }^{[19]}$ Tau mutations affecting splicing efficacy are located either in exon 10 or intron 10 and result in a change of the $4 R / 3 R$ tau mRNA ratio. ${ }^{[120,121]}$

All six tau isoforms and tau tangles in the brain of $A D$ patients are formed from both $3 R$ and $4 R$ isoforms with equal ratio, similar to healthy adults, ${ }^{[122-124]}$ however, a higher ratio of 4R/3R was observed in PSP in comparison to AD patients and healthy adults. ${ }^{[124,125]}$ Moreover, there have been several cases of PSP and frontotemporal lobar degeneration (FTLD) that had higher $4 \mathrm{R}$ tau/3R tau isoforms than FTDP-17 cases. $^{[124]}$

\section{Tau Protein in Inflammation}

Pathogenic tau molecules, by attaching to each other, form large fibrillar molecules known as tangles. However, there is evidence to suggest that smaller soluble aggregates, named oligomers are the most toxic species and are formed prior to the tangles. ${ }^{[126,127]}$ Tau oligomers may induce inflammatory signaling in the brain of patients with FTLD, AD, and other neurodegenerative diseases. These toxic oligomers are associated with neuroinflammation markers suggesting their role in chronic neuroinflammation, physiological impairments, cellular dysfunction, and ultimately, neurodegeneration. ${ }^{[128-130]}$ Oligomers co-localize with astrocytes, microglia, pro-inflammatory cytokines, and high mobility group box-1 protein (HMGB1). Moreover, astrocytes interact with tau oligomers but do not engulf them, while microglia ${ }^{[130]}$ can engulf tau oligomers, secrete them by exosomes, facilitate their propagation, and induce inflammation. ${ }^{[102]}$ Therefore, tau oligomers augment inflammation and cause more damage to cells, which may increase oligomer formation. ${ }^{[130]}$

In addition, in animal models of tauopathy, tau oligomers were detected to be associated with inflammatory cells in the retina, suggesting that the retina can be a valid and non-invasive biomarker for brain degenerative pathologies. ${ }^{[130]}$ It is notable that tau aggregates would induce ROS, resulting in inflammation in the CNS of those tauopathy patients.

\section{Pathogenic Role of p-tau in Ocular Neurode- generative Diseases}

The retina is a part of the CNS, containing various cell types, including photoreceptors, horizontal cells, amacrine cells, bipolar cells, and retinal ganglion cells (RGCs), and is easily accessible to noninvasive imaging techniques, such as scanning laser ophthalmoscopy (SLO) and optical coherence tomography (OCT). Identifying retinal pathological changes with these techniques may be used as potential biomarkers for $A D,{ }^{[131]}$ and therefore, ocular screening programs can be planned for identifying tauopathies such as AD. ${ }^{[132]}$ Although the sensitivity and specificity of non-retinal biomarkers has been determined in brain neurodegeneration, ${ }^{[133]}$ there has been no report on the sensitivity and specificity of retinal biomarkers for ocular and brain neurodegenerative disorders. Although there are reports demonstrating tau hyperphosphorylation and aggregation in ocular neurodegeneration, the actual tau pathogenicity upon the disease has not been extensively studied thus far. ${ }^{[131]}$ And so, it seems difficult to clearly demonstrate the superiority of the pathologic form of tau as a marker in conventional behavioral tests and neuroimaging.

Some of the pathological changes in AD patients include reduced thickness of the retinal nerve 
fiber layer (NFL), attenuation in retinal blood flow and venous diameter, axonal degeneration in optic nerves, decreased number of RGCs, and astrocytosis. ${ }^{[134-137]}$ Moreover, reduction of macular thickness is inversely associated with the severity of $A D{ }^{[138]}$ There is a higher incidence of AMD in patients with $A D ;{ }^{[139]}$ therefore, there is an strong correlation between $A M D$ and $A D$ incidence and the retinal changes can be used as potential biomarkers for the diagnosis of cerebral neurodegenerative diseases. ${ }^{[136,140]}$ Retinal degeneration in $A D$ was triggered by a pathogenic form of tau via calpain-mediated tau hyperphosphorylation. ${ }^{[4]}$

The presence of tau inclusions in human retinas was discovered for the first time in the corpora amylacea of the optic nerve and the retina. ${ }^{[141]}$ Pathogenic forms of tau in the form of oligomers or aggregations were detected in a variety of ocular disorders such as AMD and glaucoma. Tau was detected in various sublayers of the retina including the inner nuclear layer (INL), inner/outer plexiform layer, and NFL of the retinas from patients with $A M D{ }^{[142]} A M D$, one of the leading causes of blindness worldwide, ${ }^{[143]}$ is a complex age-related pathology that occurs as an interplay between oxidative stress, lowgrade inflammation, and aberrant accumulations of extracellular protein molecules. ${ }^{[144]}$ Induction of neuroinflammation ${ }^{[130]}$ and aggregation of tau proteins within retinal layers of cases with agerelated retinal lesions ${ }^{[145]}$ are two main methods by which tauopathy can act in the pathogenesis of AMD. Additionally, correlations between $A D$ and glaucoma have been well documented. ${ }^{[146]}$ P-tau plays a pathogenic role in the development of glaucomatous optic neuropathy and is upregulated in the retrolaminar region of the optic nerve head in glaucomatous eyes. ${ }^{[147]}$ Moreover, mislocalization of p-tau aggregates was detected in the somatodendritic compartments of RGCs that were subjected to high intraocular pressure. ${ }^{[147]}$ Importantly, tau knock-down using a targeted siRNA protected RGC somas and axons from hypertension-induced damage. ${ }^{[148]}$ Tau oligomers were detected in the retina of an animal model of glaucoma and it was observed that tau inhibition could reduce retinal degeneration. ${ }^{[148]}$ Moreover, it was demonstrated that calpains, proteins belonging to a family of calcium-dependent and nonlysosomal cysteine proteases are activated after ocular hypertension, a condition in which increase of calcium in the retinas and increase of calpaindependent proteolysis of tau occurs that leads to neuronal cell death. ${ }^{[149,150]}$ It is noteworthy that augmentation of hyperphosphorylated tau has been identified in the vitreous samples of diabetic retinopathies that represent a form of ocular degeneration. ${ }^{[151]}$

AT8 tau with phosphorylation profile at $\mathrm{Ser}^{202}$ and $\mathrm{Thr}^{205}$ has been well characterized, and AT8 antibody was used to stage human neuropathological diseases. ${ }^{[152]}$ AT8 hyperphosphorylated tau was detected in the outer border of the INL and specifically in the inner plexiform layer (IPL) of glaucomatous retinas. In addition, this form of tau colocalizes with parvalbumin in the retinal horizontal cells. ${ }^{[153]}$ AT8 tau protein was also detected with $A \beta$ depositions in various retinal layers including the RGC layer, IPL, INL, outer plexiform layer (OPL), and outer nuclear layer (ONL) in Tg2576 mice. ${ }^{[154]}$

Photoreceptor cells have high energy demands and are significantly affected by ageing. ${ }^{[155,156]}$ Tau aggregates were observed within the cytoplasm of rod and cone photoreceptors, and a positive correlation was observed between age and the number of inclusions in these cells. ${ }^{[145]}$ Conversely, $\mathrm{p}$-tau is specifically accumulated in primate cones while reducing the cellular functions. ${ }^{[12]}$ Diffuse tau aggregates were found in the retinal INL of enucleated eyes that had abnormal retinal changes. They were also detected in the cytoplasm of several photoreceptor cells in patients older than 63 years, and a positive correlation was observed between the patients' age and the numbers of RGCs with tau aggregates. In addition, aggregated tau was found within the cytoplasm of photoreceptor cells in the majority of patients above 63 years of age. ${ }^{[145]} \mathrm{OA}$, one of the positive regulators of $\mathrm{p}$ tau accumulation, was shown to have a destructive role in the cytoskeleton network and growth-cone cells. ${ }^{[157]}$

Transgenic mice expressing P301S mutant human tau model tauopathy develop hyperphosphorylated tau aggregations in the CNS. P301S mutant tau carries a substitution of Ser instead of Pro in exon 10 of the MAPT gene. ${ }^{[158]}$ In P301S retinas, hyperphosphorylated tau molecules are aggregated in the nerve fiber and RGC layers. Also, RGC axonal outgrowth did not respond to neurotrophic stimuli in retinal explants cultured from P301S mice, suggesting that pathogenic tau can change neurotrophic signaling. ${ }^{[159]}$ Moreover, 
the mild tauopathy that developed in RGCs of P301S mice induced functional retinal changes and neuronal dysfunction by disrupting brainderived neurotrophic factor (BDNF) signaling, via the TrkB receptor that is essential for neuronal survival and synaptic plasticity. ${ }^{[160]}$ Moreover, P301S tau aggregates in RGCs were associated with a reduction in anterograde and retrograde axonal transport in vivo, with a markedly increased effect of excitotoxic injury. ${ }^{[161]}$

Another tau gene mutation is P301L that expresses Leu instead of Pro at position 301 in both the shortest and longest four repeat tau isoforms, and forms NFTs in the CNS. ${ }^{[162]}$ Age-related neurodegenerative changes with significant reduced thickness of retinal INL were observed in P301L mice, and these changes were more pronounced at the peripheral areas and with increasing age. Furthermore, an increase in the size of the RGCs obtained from tau P301L mice was observed with increasing age, in contrast to control mice in which RGC sizes decreased with increasing age. ${ }^{[163]}$

The dynactin complex plays a pivotal role in the transportation network in many cell types by mediating the binding of MT motor complex dynein to its cargoes. ${ }^{[164]}$ Tau and dynactin have extensive interactions, and dynactin attachment to MTs is facilitated by the binding of tau N-terminal domain to the C-terminus of the p150 subunit of dynactin. ${ }^{[28]}$ Mutation in the arginine residue in the $\mathrm{N}$-terminal domain of tau was detected in patients with FTDP-17 that affects tau binding to dynactin, and tau was abnormally distributed in the RGC axons of tau P301S transgenic mice. ${ }^{[28]}$ However, recombinant human tau promoted the attachment of the dynactin complex to axonal microtubules, which indicates a potential role of tau in axonal transportation. ${ }^{[28]}$

Transportation of organelles such as mitochondria and peroxisomes by kinesin molecules was inhibited in rat RGCs with abnormally aggregated tau, evidencing the essential role of tau in kinesinmediated transportation. Thus, rat RGCs with accumulated tau suffered from loss of energy production and accumulation of ROS due to perturbation of mitochondria and peroxisome function. Moreover, the rate of anterograde transportation that include vesicles necessary for growth cones and synaptic function was slower. ${ }^{[165]}$

Oxidative damage was shown to be associated with death of cones in retinitis pigmentosa, and of both photoreceptor cell types, in AMD. ${ }^{166]}$ Thioredoxin 1 (TRX1) in the retina plays a protective role against photooxidative damage. ${ }^{[167]}$ Rodderived cone viability factor (RdCVF) is a member of the thioredoxins family ${ }^{[168]}$ and a trophic factor secreted by rods for maintaining cone viability and functionality. ${ }^{[169]}$ In murine models, RdCVF is encoded by the $N x n / 1$ gene that also encodes for a second polypeptide, RdCVFL, by alternative splicing. RdCVFL inhibits tau phosphorylation and protects tau from oxidative damage. ${ }^{[170]}$ Upregulation of tau phosphorylation has been well demonstrated in the retinas of $N x n / 1-/-$ mice. ${ }^{[171,172]}$ Therefore, therapeutic modalities augmenting the $N X N L 1$ gene or the corresponding protein may be promising for the treatment of cerebral and ocular neurodegeneration.

\section{Therapeutic Strategies for Targeting Patho- logic Tau}

The pathogenic tau molecule is an excellent therapeutic target for neurodegenerative diseases using several strategies such as reducing levels, altering post-translational modifications, or blocking propagation of pathogenic tau.

Several tauopathy-based targeted therapies for neurodegenerative diseases have been introduced, such as suppressing tau misfolding, ${ }^{[173]}$ targeting tau acetylation, ${ }^{[174]}$ inhibiting tauinduced proteasome impairment, ${ }^{[175]}$ and tau immunotherapy. ${ }^{[176-180]}$ Several therapeutic modalities for inhibiting tau aggregation have been reported, ${ }^{[19,181]}$ among which, the use of small molecules has recently gained much interest.

Several small molecules exhibit anti-tau aggregation properties; ${ }^{[182,183]}$ one of these is D-enantiomeric peptides that has modulating mechanisms on tau self-aggregation. ${ }^{[184]}$ Other small molecules that were shown to have antitau aggregation effects have an eight amino acid peptide named NAP (Davunetide). ${ }^{[185]}$ Clinically, NAP (davunetide) exhibited its efficacy in prodromal $A D$ patients that had equal $3 R$ and 4R Tau isoforms but not in the PSP cases that had increased 4R Tau. ${ }^{[186]}$ Cationic small molecules and cationic osmolyte urea also have inhibitory effects on tau accumulation. ${ }^{[187-189]}$ Moreover, the inhibitory effect of a cationic polymer polyethyleneimine and a cationic polypeptide arginine on the aggregation of VQIVYK and 
GKVQIINKLDL peptides in tau protein was also observed. ${ }^{[190]}$

Antisense oligonucleotides are other small molecules that selectively downregulate human tau at mRNA and protein levels in adult mouse brain that express mutant P301S human tau. ${ }^{[191]}$ Moreover, the chaperone Artemin was found to be an effective inhibitor of tau inclusions in both physiologic and supraphysiologic concentrations, in a dose-dependent manner and in a cell-free model system. This supports the idea that Artemin can be a therapeutic option for people with $A D{ }^{[192]}$

Although several specific small molecules for targeting pathogenic tau have been discovered, more studies are needed to illustrate the safety and efficacy of these molecules as novel drugs. More importantly, it is of crucial importance to clarify which epitope to target?

We herein studied latest reports on tau pathology; especially in ocular neurodegeneration. Although we may not clearly describe the pathogenic tau species playing part in ocular neurodegeneration, however, due to similarities between brain and eye neurodegeneration, the aforementioned treatment modalities for brain tauopathies sound like efficient therapeutic strategies in fighting with the ocular neurodegeneration.

\section{Summary}

The current review, based on numerous studies on the role of pathogenic tau in neurodegeneration, attempts to highlight the connection between brain and eye diseases. Pathogenic tau protein exerts destructive effects that are associated with cerebral degenerations such as AD, PSP, and TBI, and ocular neurodegenerative disorders such as AMD, glaucoma/ocular hypertension, and probably diabetic retinopathy. The destructive effects of the pathogenic form of tau can be exerted by several forms of tau such as soluble oligomers, insoluble aggregates, or even by cis p-tau which is an early driver of pathogenic tau. Considering this evidence, targeted therapy based on pathogenic tau could be a promising therapeutic for patients with CNS or ocular neurodegeneration, to not only prevent the more destructive effects of pathogenic tau, but also restore normal functioning to neural cells. Moreover, with the identification of tauopathy-related retinal changes with noninvasive imaging techniques, screening programs for the early diagnosis of CNS tauopathies such as AD can be planned.

\section{Financial Support and Sponsorship}

Nil.

\section{Conflicts of Interest}

There are no conflicts of interest.

\section{REFERENCES}

1. Weingarten MD, Lockwood AH, Hwo S-Y, Kirschner MW. A protein factor essential for microtubule assembly. Proc Natl Acad Sci 1975;72:1858-1862.

2. Andreadis A. Misregulation of tau alternative splicing in neurodegeneration and dementia. Prog Mol Subcell Biol 2006;44:89-107.

3. LoPresti P, Szuchet S, Papasozomenos SC, Zinkowski RP, Binder LI. Functional implications for the microtubuleassociated protein tau: localization in oligodendrocytes. Proc Natl Acad Sci 1995;92:10369-10373.

4. Dehmelt L, Halpain S. The MAP2/Tau family of microtubule-associated proteins. Genome Biol 2004;6:204.

5. Feinstein SC, Wilson L. Inability of tau to properly regulate neuronal microtubule dynamics: a loss-of-function mechanism by which tau might mediate neuronal cell death. Biochim Biophys Acta 2005;1739:268-279.

6. Mandelkow E-M, Mandelkow E. Biochemistry and cell biology of tau protein in neurofibrillary degeneration. Cold Spring Harb Perspect Med 2012;2:a006247.

7. Khatoon S, Grundke-lqbal I, Iqbal K. Levels of normal and abnormally phosphorylated tau in different cellular and regional compartments of Alzheimer disease and control brains. FEBS Lett 1994;351:80-84.

8. Spires-Jones TL, Stoothoff WH, de Calignon A, Jones PB, Hyman BT. Tau pathophysiology in neurodegeneration: a tangled issue. Trends Neurosci 2009;32:150-159.

9. Shahani N, Brandt R. Functions and malfunctions of the tau proteins. Cell Mol Life Sci 2002;59:1668-1680.

10. Wang $\mathrm{Y}$, Mandelkow E. Tau in physiology and pathology. Nat Rev Neurosci 2016;17:22.

11. Mazzaro N, Barini E, Spillantini MG, Goedert M, Medini P, Gasparini L. Tau- driven neuronal and neurotrophic dysfunction in a mouse model of early tauopathy. $J$ Neurosci 2016;36:2086-2100.

12. Aboelnour A, Van der Spuy J, Powner M, Jeffery G. Primate retinal cones express phosphorylated tau associated with neuronal degeneration yet survive in old age. Exp Eye Res 2017;165:105-108.

13. Gupta N, Fong J, Ang LC, Yucel YH. Retinal tau pathology in human glaucomas. Can J Ophthalmol 2008;43:53-60.

14. Liu F, Gong CX. Tau exon 10 alternative splicing and tauopathies. Mol Neurodegener 2008;3:8. 
15. Lee G, Cowan N, Kirschner M. The primary structure and heterogeneity of tau protein from mouse brain. Science 1988;239:285-288.

16. Goedert M, Spillantini MG, Jakes R, Rutherford D, Crowther RA. Multiple isoforms of human microtubule-associated protein tau: sequences and localization in neurofibrillary tangles of Alzheimer's disease. Neuron 1989;3:519-526.

17. Avila J, Jiménez JS, Sayas CL, Bolós M, Zabala JC, Rivas G, et al. Tau structures. Front Aging Neurosci 2016;8:262.

18. Martin L, Latypova X, Wilson CM, Magnaudeix A, Perrin $\mathrm{M}-\mathrm{L}$, Yardin C, et al. Tau protein kinases: involvement in Alzheimer's disease. Ageing Res Rev 2013;12:289-309.

19. Boutajangout A, Wisniewski T. Tau-based therapeutic approaches for Alzheimer's disease-a mini-review. Gerontology 2014;60:381-385.

20. McMillan P, Korvatska E, Poorkaj P, Evstafjeva Z, Robinson L, Greenup L, et al. Tau isoform regulation is region-and cell-specific in mouse brain. J Comp Neurol 2008;511:788-803.

21. Jeganathan S, von Bergen M, Mandelkow E-M, Mandelkow $\mathrm{E}$. The natively unfolded character of tau and its aggregation to Alzheimer-like paired helical filaments. Biochemistry 2008;47:10526-10539.

22. Mukrasch MD, Bibow S, Korukottu J, Jeganathan S, Biernat J, Griesinger C, et al. Structural polymorphism of 441-residue tau at single residue resolution. PLOS Biol 2009;7:e34.

23. Sillen A, Barbier P, Landrieu I, Lefebvre S, Wieruszeski $\mathrm{J}-\mathrm{M}$, Leroy $\mathrm{A}$, et al. NMR investigation of the interaction between the neuronal protein tau and the microtubules. Biochemistry 2007;46:3055-3064.

24. Chen J, Kanai Y, Cowan N, Hirokawa N. Projection domains of MAP2 and tau determine spacings between microtubules in dendrites and axons. Nature 1992;360:674.

25. Liu C, Götz J. Profiling murine tau with $\mathrm{ON}, 1 \mathrm{~N}$ and $2 \mathrm{~N}$ isoform-specific antibodies in brain and peripheral organs reveals distinct subcellular localization, with the $1 \mathrm{~N}$ isoform being enriched in the nucleus. PLOS ONE 2013;8:e84849.

26. Brandt R, Léger J, Lee G. Interaction of tau with the neural plasma membrane mediated by tau's amino-terminal projection domain. J Cell Biol 1995;131:1327-1340.

27. Gauthier-Kemper A, Weissmann C, Golovyashkina N, Sebö-Lemke Z, Drewes G, Gerke V, et al. The frontotemporal dementia mutation R406W blocks tau's interaction with the membrane in an annexin A2-dependent manner. J Cell Biol 2011;192:647-661.

28. Magnani E, Fan J, Gasparini L, Golding M, Williams M, Schiavo $G$, et al. Interaction of tau protein with the dynactin complex. EMBO J 2007;26:4546-4554.

29. Liu C, Song X, Nisbet R, Götz J. Co-immunoprecipitation with tau isoform-specific antibodies reveals distinct protein interactions, and highlights a putative role for $2 \mathrm{~N}$ tau in disease. J Biol Chem 2016;291:8173-8188.

30. Morris M, Maeda S, Vossel K, Mucke L. The many faces of tau. Neuron 2011;70:410-426.

31. Flanagan LA, Cunningham CC, Chen J, Prestwich GD, Kosik KS, Janmey PA. The structure of divalent cationinduced aggregates of PIP2 and their alteration by gelsolin and tau. Biophys J 1997;73:1440-1447.
32. Surridge CD, Burns RG. The difference in the binding of phosphatidylinositol distinguishes MAP2 from MAP2C and Tau. Biochemistry 1994;33:8051-8057.

33. Qi H, Cantrelle Fo-X, Benhelli-Mokrani H, Smet-Nocca C, Buée L, Lippens $G$, et al. Nuclear magnetic resonance spectroscopy characterization of interaction of Tau with DNA and its regulation by phosphorylation. Biochemistry 2015;54:1525-1533.

34. Wang XS, Wang DL, Zhao J, Qu MH, Zhou XH, He HJ, et al. The proline-rich domain and the microtubule binding domain of protein tau acting as RNA binding domains. Protein Pept Lett 2006;13:679-685.

35. Eidenmüller J, Thomas F, Thorsten M, Madeline P, Sontag E, Brandt R. Phosphorylation-mimicking glutamate clusters in the proline-rich region are sufficient to simulate the functional deficiencies of hyperphosphorylated tau protein. Biochem J 2001;357:759-767.

36. Goode BL, Denis PE, Panda D, Radeke MJ, Miller HP, Wilson $\mathrm{L}$, et al. Functional interactions between the prolinerich and repeat regions of tau enhance microtubule binding and assembly. Mol Biol Cell 1997;8:353-365.

37. He HJ, Wang XS, Pan R, Wang DL, Liu MN, He RQ. The proline-rich domain of tau plays a role in interactions with actin. BMC Cell Biol 2009;10:81.

38. Gong C-X, Liu F, Grundke-lqbal I, lqbal K. Post-translational modifications of tau protein in Alzheimer's disease. $J$ Neural Transm 2005;112:813-838.

39. Martin L, Latypova X, Terro F. Post-translational modifications of tau protein: implications for Alzheimer's disease. Neurochem Int 2011;58:458-471.

40. Min S-W, Chen X, Tracy TE, Li Y, Zhou Y, Wang C, et al. Critical role of acetylation in tau-mediated neurodegeneration and cognitive deficits. Nat Med 2015;21:1154-1162.

41. Xu L, Zheng J, Margittai M, Nussinov R, Ma B. How does hyperphopsphorylation promote tau aggregation and modulate filament structure and stability? ACS Chem Neurosci 2016;7:565-575.

42. Iqbal K, Liu F, Gong C-X. Tau and neurodegenerative disease: the story so far. Nat Rev Neurol 2016;12:15-27.

43. Ballatore C, Lee VM-Y, Trojanowski JQ. Tau-mediated neurodegeneration in Alzheimer's disease and related disorders. Nat Rev Neurosci 2007;8:663-672.

44. Zhao $\mathrm{H}$, Chang $\mathrm{R}$, Che $\mathrm{H}$, Wang J, Yang L, Fang $\mathrm{W}$, et al. Hyperphosphorylation of tau protein by calpain regulation in retina of Alzheimer's disease transgenic mouse. Neurosci Lett 2013;551:12-16.

45. Morris M, Knudsen GM, Maeda S, Trinidad JC, loanoviciu $A$, Burlingame $A L$, et al. Tau post-translational modifications in wild-type and human amyloid precursor protein transgenic mice. Nat Neurosci 2015;18:1183-1189.

46. Rodríguez SM, Gallardo AS, Pereyra PG, Macías M, Ordaz $\mathrm{B}$, Ortega FP, et al. Phosphorylation of tau protein correlates with changes in hippocampal theta oscillations and reduces hippocampal excitability in Alzheimer's model. $J$ Biol Chem 2018;293:8462-8472.

47. Hanger DP, Betts JC, Loviny TL, Blackstock WP, Anderton $\mathrm{BH}$. New phosphorylation sites identified in hyperphosphorylated tau (paired helical filament-tau) from Alzheimer's disease brain using nanoelectrospray mass spectrometry. J Neurochem 1998;71:2465-2476. 
48. Strong M, Yang W, Strong W, Leystra-Lantz C, Jaffe H, Pant $\mathrm{H}$. Tau protein hyperphosphorylation in sporadic ALS with cognitive impairment. Neurology 2006;66:1770-1771.

49. Yang W, Sopper MM, Leystra-Lantz C, Strong MJ. Microtubule-associated tau protein positive neuronal and glial inclusions in ALS. Neurology 2003;61:1766-1773.

50. Yang W, Leystra-Lantz C, Strong MJ. Upregulation of GSK3 $\beta$ expression in frontal and temporal cortex in ALS with cognitive impairment (ALSci). Brain Res 2008;1196:131-139.

51. Yang W, Strong MJ. Widespread neuronal and glial hyperphosphorylated tau deposition in ALS with cognitive impairment. Amyotroph Lateral Scler 2012;13:178-193.

52. Behrouzi R, Liu X, Wu D, Robinson AC, TanaguchiWatanabe S, Rollinson S, et al. Pathological tau deposition in Motor Neurone Disease and frontotemporal lobar degeneration associated with TDP-43 proteinopathy. Acta Neuropathol Commun 2016;4:33.

53. Reynolds $\mathrm{CH}$, Betts JC, Blackstock WP, Nebreda AR, Anderton $\mathrm{BH}$. Phosphorylation sites on tau identified by nanoelectrospray mass spectrometry. J Neurochem 2000;74:1587-1595.

54. Gohar M, Yang W, Strong W, Volkening K, Leystra-Lantz C, Strong MJ. Tau phosphorylation at threonine-175 leads to fibril formation and enhanced cell death: implications for amyotrophic lateral sclerosis with cognitive impairment. $J$ Neurochem 2009;108:634-643.

55. Moszczynski AJ, Gohar M, Volkening K, Leystra-Lantz C, Strong W, Strong MJ. Thr 175-phosphorylated tau induces pathologic fibril formation via GSK3 $\beta$-mediated phosphorylation of Thr 231 in vitro. Neurobiol Aging. 2015;36:1590-1599.

56. Hampel H, Blennow K, Shaw LM, Hoessler YC, Zetterberg $\mathrm{H}$, Trojanowski JQ. Total and phosphorylated tau protein as biological markers of Alzheimer's disease. Exp Gerontol 2010;45:30-40.

57. Gong C-X, Lidsky T, Wegiel J, Zuck L, Grundke-lqbal I, Iqbal K. Phosphorylation of microtubule-associated protein tau is regulated by protein phosphatase $2 \mathrm{~A}$ in mammalian brain implications for neurofibrillary degeneration in Alzheimer's disease. J Biol Chem 2000;275:55355544.

58. Boban M, Miskic T, Leko MB, Hof PR, Simic G. Human neuroblastoma SH-SY5Y cells treated with okadaic acid express phosphorylated high molecular weight tau immunoreactive protein species. J Neurosci Methods 2018:284265.

59. Abrahamson M, Barrett AJ, Salvesen G, Grubb A. Isolation of six cysteine proteinase inhibitors from human urine. Their physicochemical and enzyme kinetic properties and concentrations in biological fluids. $J$ Biol Chem 1986;261:11282-11289.

60. Deng A, Irizarry MC, Nitsch RM, Growdon JH, Rebeck GW. Elevation of cystatin $C$ in susceptible neurons in Alzheimer's disease. Am J Pathol 2001;159:1061-1068.

61. Mathews PM, Levy E. Cystatin C in aging and in Alzheimer's disease. Ageing Res Rev 2016;32:38-50.

62. Duan J, Marcellus KA, Qin X, Wang Y, Paudel HK. Cystatin $C$ promotes tau protein phosphorylation and causes microtubule instability by inhibiting intracellular turnover of GSK3 $\beta$ in neurons. Mol Cell Neurosci 2018; 89:1-8.
63. Bramblett GT, Goedert M, Jakes R, Merrick SE, Trojanowski JQ, Lee VM. Abnormal tau phosphorylation at Ser 396 in Alzheimer's disease recapitulates development and contributes to reduced microtubule binding. Neuron 1993;10:1089-1099.

64. Pei J-J, Braak E, Braak H, Grundke-lqbal I, Iqbal K, Winblad $B$, et al. Distribution of active glycogen synthase kinase $3 \beta$ (GSK-3 $\beta$ ) in brains staged for Alzheimer disease neurofibrillary changes. J Neuropathol Exp Neurol 1999;58:10101019.

65. Pei J-J, Tanaka T, Tung Y-C, Braak E, lqbal K, GrundkeIqbal I. Distribution, levels, and activity of glycogen synthase kinase- 3 in the Alzheimer disease brain. $J \mathrm{Neu}$ ropathol Exp Neurol 1997;56:70-78.

66. Yamaguchi $\mathrm{H}$, Ishiguro K, Uchida T, Takashima A, Lemere CA, Imahori K. Preferential labeling of Alzheimer neurofibrillary tangles with antisera for tau protein kinase (TPK) I/glycogen synthase kinase-3 $\beta$ and cyclin-dependent kinase 5, a component of TPK II. Acta Neuropathol 1996;92:232-241.

67. Hooper C, Killick R, Lovestone S. The GSK3 hypothesis of Alzheimer's disease. J Neurochem 2008;104:1433-1439.

68. Leroy K, Yilmaz Z, Brion JP. Increased level of active GSK$3 \beta$ in Alzheimer's disease and accumulation in argyrophilic grains and in neurones at different stages of neurofibrillary degeneration. Neuropathol Appl Neurobiol 2007;33:4355.

69. Nikolic M, Dudek H, Kwon YT, Ramos YF, Tsai LH. The cdk5/p35 kinase is essential for neurite outgrowth during neuronal differentiation. Genes Dev 1996;10:816-825.

70. Kondo A, Shahpasand K, Mannix R, Qiu J, Moncaster J, Chen $\mathrm{C}-\mathrm{H}$, et al. Antibody against early driver of neurodegeneration cis P-tau blocks brain injury and tauopathy. Nature 2015;523:431-436.

71. Ward SM, Himmelstein DS, Lancia JK, Binder LI. Tau oligomers and tau toxicity in neurodegenerative disease. Biochem Soc Trans 2012; 40:667-671.

72. Von Bergen M, Barghorn S, Biernat J, Mandelkow E-M, Mandelkow E. Tau aggregation is driven by a transition from random coil to beta sheet structure. Biochim Biophys Acta 2005;1739:158-166.

73. Ganguly P, Do TD, Larini L, LaPointe NE, Sercel AJ, Shade MF, et al. Tau assembly: the dominant role of PHF6 (VQIVYK) in microtubule binding region repeat R3. J Phys Chem B 2015;119:4582-4593.

74. von Bergen M, Barghorn S, Li L, Marx A, Biernat J, Mandelkow E-M, et al. Mutations of tau protein in frontotemporal dementia promote aggregation of paired helical filaments by enhancing local $\beta$-structure. J Biol Chem 2001;276:48165-48174.

75. Peterson DW, Zhou H, Dahlquist FW, Lew J. A soluble oligomer of tau associated with fiber formation analyzed by NMR. Biochemistry 2008;47:7393-7404.

76. Meraz-Ríos MA, Lira-De León KI, Campos-Peña V, De Anda-Hernández MA, Mena-López R. Tau oligomers and aggregation in Alzheimer's disease. J Neurochem 2010;112:1353-1367.

77. Alonso AD, Zaidi T, Novak M, Barra HS, Grundke-lqbal I, Iqbal K. Interaction of tau isoforms with Alzheimer's disease abnormally hyperphosphorylated tau and in vitro phosphorylation into the disease-like protein. $\mathrm{J} \mathrm{Biol} \mathrm{Chem}$ 2001;276:37967-37973. 
78. Hasegawa M, Watanabe S, Kondo H, Akiyama H, Mann $\mathrm{DM}$, Saito $\mathrm{Y}$, et al. $3 \mathrm{R}$ and $4 \mathrm{R}$ tau isoforms in paired helical filaments in Alzheimer's disease. Acta Neuropathol 2014;127:303-305.

79. Lewis J, McGowan E, Rockwood J, Melrose H, Nacharaju P, Van Slegtenhorst M, et al. Neurofibrillary tangles, amyotrophy and progressive motor disturbance in mice expressing mutant (P301L) tau protein. Nat Genet 2000;25:402-405.

80. Zhong Q, Congdon EE, Nagaraja HN, Kuret J. Tau isoform composition influences the rate and extent of filament formation. J Biol Chem 2012;287:20711-10719.

81. Kuret J, Chirita CN, Congdon EE, Kannanayakal T, Li G, Necula M, et al. Pathways of tau fibrillization. Biochim Biophys Acta 2005;1739:167-178.

82. Sibille N, Sillen A, Leroy A, Wieruszeski J-M, Mulloy B, Landrieu I, et al. Structural impact of heparin binding to fulllength Tau as studied by NMR spectroscopy. Biochemistry 2006;45:12560-12572.

83. Wilson DM, Binder LI. Free fatty acids stimulate the polymerization of tau and amyloid beta peptides. In vitro evidence for a common effector of pathogenesis in Alzheimer's disease. Am J Pathol 1997;150:2181.

84. Iqbal K, Grundke-lqbal I. Ubiquitination and abnormal phosphorylation of paired helical filaments in Alzheimer's disease. Mol Neurobiol 1991;5:399-410.

85. Neddens J, Temmel M, Flunkert S, Kerschbaumer B, Hoeller C, Loeffler T, et al. Phosphorylation of different tau sites during progression of Alzheimer's disease. Acta Neuropathol Commun 2018;6:52.

86. Lin YT, Cheng JT, Liang LC, Ko CY, Lo YK, Lu PJ. The binding and phosphorylation of Thr231 is critical for Tau's hyperphosphorylation and functional regulation by glycogen synthase kinase 3ß. J Neurochem 2007;103:802-813.

87. Von Bergen M, Barghorn S, Biernat J, Mandelkow E-M, Mandelkow E. Tau aggregation is driven by a transition from random coil to beta sheet structure. Biochim Biophys Acta 2005;1739:158-166.

88. Kolarova M, García-Sierra F, Bartos A, Ricny J, Ripova D. Structure and pathology of tau protein in Alzheimer disease. Int J Alzheimers Dis 2012;2012:731526.

89. de Calignon A, Polydoro M, Suárez-Calvet M, William C, Adamowicz DH, Kopeikina KJ, et al. Propagation of tau pathology in a model of early Alzheimer's disease. Neuron 2012;73:685-697.

90. Goedert M. Alzheimer's and Parkinson's diseases: The prion concept in relation to assembled $A \beta$, tau, and $\alpha$ synuclein. Science 2015;349:1255555.

91. Pooler AM, Polydoro M, Wegmann S, Nicholls SB, SpiresJones TL, Hyman BT. Propagation of tau pathology in Alzheimer's disease: identification of novel therapeutic targets. Alzheimers Res Ther 2013;5:49.

92. Mohamed NV, Herrou T, Plouffe V, Piperno N, Leclerc N. Spreading of tau pathology in Alzheimer's disease by cellto-cell transmission. Eur J Neurosci 2013;37:1939-1948.

93. Wegmann S, Bennett RE, Amaral AS, Hyman BT. Studying tau protein propagation and pathology in the mouse brain using adeno-associated viruses. Methods Cell Biol 2017;141:307-322.

94. Bilkei-Gorzo A. Genetic mouse models of brain ageing and Alzheimer's disease. Pharmacol Ther 2014;142:244-257.
95. Ojo JO, Mouzon BC, Crawford F. Repetitive head trauma, chronic traumatic encephalopathy and tau: Challenges in translating from mice to men. Exp Neurol 2016;275:389404.

96. Kanaan NM, Pigino GF, Brady ST, Lazarov O, Binder LI, Morfini GA. Axonal degeneration in Alzheimer's disease: when signaling abnormalities meet the axonal transport system. Exp Neurol 2013;246:44-53.

97. Hernandez F, Avila J. Tauopathies. Cell Mol Life Sci 2007;64:2219-2233.

98. Lee VM, Goedert M, Trojanowski JQ. Neurodegenerative tauopathies. Annu Rev Neurosci 2001;24:1121-1159.

99. Leyns CE, Holtzman DM. Glial contributions to neurodegeneration in tauopathies. Mol Neurodegener 2017;12:50.

100. Chen JA, Chen Z, Won H, Huang AY, Lowe JK, Wojta K, et al. Joint genome-wide association study of progressive supranuclear palsy identifies novel susceptibility loci and genetic correlation to neurodegenerative diseases. Mol Neurodegener 2018;13:41.

101. Ferrer I, García MA, Carmona M, Andrés-Benito P, Torrejón-Escribano B, Garcia-Esparcia P, et al. Involvement of oligodendrocytes in tau seeding and spreading in tauopathies. Front Aging Neurosci 2019;11:112.

102. Asai H, Ikezu S, Tsunoda S, Medalla M, Luebke J, Haydar $\mathrm{T}$, et al. Depletion of microglia and inhibition of exosome synthesis halt tau propagation. Nat Neurosci 2015;18:1584.

103. Johnson VE, Stewart W, Smith DH. Widespread tau and amyloid-beta pathology many years after a single traumatic brain injury in humans. Brain Pathol 2012;22:142149.

104. McKee AC, Stein TD, Kiernan PT, Alvarez VE. The neuropathology of chronic traumatic encephalopathy. Brain Pathol 2015;25:350-364.

105. Blennow K, Hardy J, Zetterberg H. The neuropathology and neurobiology of traumatic brain injury. Neuron 2012;76:886-899.

106. Kandimalla R, Manczak M, Fry D, Suneetha Y, Sesaki $\mathrm{H}$, Reddy $\mathrm{PH}$. Reduced dynamin-related protein 1 protects against phosphorylated tau-induced mitochondrial dysfunction and synaptic damage in Alzheimer's disease. Hum Mol Genet 2016;25:4881-4897.

107. Wang H-H, Li H-L, Liu R, Zhang Y, Liao K, Wang Q, et al. Tau overexpression inhibits cell apoptosis with the mechanisms involving multiple viability-related factors. $J$ Alzheimers Dis 2010;21:167-179.

108. Li H-L, Wang H-H, Liu S-J, Deng Y-Q, Zhang Y-J, Tian $Q$, et al. Phosphorylation of tau antagonizes apoptosis by stabilizing $\beta$-catenin, a mechanism involved in Alzheimer's neurodegeneration. Proc Natl Acad Sci 2007;104:35913596.

109. Chung W-S, Welsh CA, Barres BA, Stevens B. Do glia drive synaptic and cognitive impairment in disease? Nat Neurosci 2015;18:1539.

110. Rosenfeld PJ, Brown DM, Heier JS, Boyer DS, Kaiser PK, Chung $\mathrm{CY}$, et al. Ranibizumab for neovascular age-related macular degeneration. N Engl J Med 2006;355:1419-1431.

111. Moszczynski AJ, Strong W, Xu K, Mckee A, Brown A, Strong MJ. Pathologic Thr175 tau phosphorylation in CTE and CTE with ALS. Neurology 2018;90:e380-e387.

112. Bloom GS. Amyloid- $\beta$ and tau: the trigger and bullet in Alzheimer disease pathogenesis. JAMA Neurol 2014;71:505-508. 
113. Lloret A, Badia M-C, Giraldo E, Ermak G, Alonso M-D, Pallardó FV, et al. Amyloid- $\beta$ toxicity and tau hyperphosphorylation are linked via RCAN1 in Alzheimer's disease. $J$ Alzheimers Dis 2011;27:701-709.

114. Götz J, Chen FV, Van Dorpe J, Nitsch R. Formation of neurofibrillary tangles in $\mathrm{P} 301 \mathrm{~L}$ tau transgenic mice induced by Aß42 fibrils. Science 2001;293:1491-1495.

115. Lewis J, Dickson DW, Lin W-L, Chisholm L, Corral A, Jones $G$, et al. Enhanced neurofibrillary degeneration in transgenic mice expressing mutant tau and APP. Science 2001;293:1487-1491.

116. Badiola N, De Oliveira RM, Herrera F, Guardia-Laguarta $\mathrm{C}$, Gonçalves SA, Pera M, et al. Tau enhances $\alpha$-synuclein aggregation and toxicity in cellular models of synucleinopathy. PLOS ONE 2011;6:e26609.

117. Marui W, Iseki E, Uéda K, Kosaka K. Occurrence of human $\alpha$-synuclein immunoreactive neurons with neurofibrillary tangle formation in the limbic areas of patients with Alzheimer's disease. J Neurol Sci 2000;174:81-84.

118. Qureshi HY, Paudel HK. Parkinsonian neurotoxin 1-methyl4-phenyl-1, 2, 3, 6-tetrahydropyridine (MPTP) and $\alpha$ synuclein mutations promote Tau protein phosphorylation at Ser262 and destabilize microtubule cytoskeleton in vitro. J Biol Chem 2011;286:5055-5068.

119. Foster NL, Wilhelmsen K, Sima AA, Jones MZ, D’Amato CJ, Gilman S, et al. Frontotemporal dementia and parkinsonism linked to chromosome 17: a consensus conference. Ann Neurol 1997;41:706-715.

120. Hutton M, Lendon CL, Rizzu P, Baker M, Froelich S, Houlden $\mathrm{H}$, et al. Association of missense and $5^{\prime}$-splicesite mutations in tau with the inherited dementia FTDP-17. Nature 1998;393:702.

121. Varani L, Hasegawa M, Spillantini MG, Smith MJ, Murrell JR, Ghetti B, et al. Structure of tau exon 10 splicing regulatory element RNA and destabilization by mutations of frontotemporal dementia and parkinsonism linked to chromosome 17. Proc Natl Acad Sci 1999;96:8229-8234.

122. Goedert M, Spillantini M, Jakes R, Crowtherp R, Vanmechelen E, Probst A, et al. Molecular dissection of the paired helical filament. Neurobiol Aging 1995;16:325-334.

123. Ingelsson M, Ramasamy K, Cantuti-Castelvetri I, Skoglund L, Matsui T, Orne J, et al. No alteration in tau exon 10 alternative splicing in tangle-bearing neurons of the Alzheimer's disease brain. Acta Neuropathol 2006;112:439-449.

124. Chambers CB, Lee JM, Troncoso JC, Reich S, Muma NA. Overexpression of four-repeat tau mRNA isoforms in progressive supranuclear palsy but not in Alzheimer's disease. Ann Neurol 1999;46:325-332.

125. Ingelsson M, Ramasamy K, Russ C, Freeman SH, Orne J, Raju S, et al. Increase in the relative expression of tau with four microtubule binding repeat regions in frontotemporal lobar degeneration and progressive supranuclear palsy brains. Acta Neuropathol 2007;114:471-479.

126. Patterson KR, Remmers C, Fu Y, Brooker S, Kanaan $\mathrm{NM}$, Vana $\mathrm{L}$, et al. Characterization of prefibrillar tau oligomers in vitro and in Alzheimers disease. $\mathrm{J} \mathrm{Biol} \mathrm{Chem}$ 2011;286:23063-23076.

127. Lasagna-Reeves CA, L Castillo-Carranza D, R Jackson $G$, Kayed R. Tau oligomers as potential targets for immunotherapy for Alzheimer's disease and tauopathies. Curr Alzheimer Res 2011;8:659-665.
128. Garwood CJ, Cooper JD, Hanger DP, Noble W. Antiinflammatory impact of minocycline in a mouse model of tauopathy. Front Psychiatry. 2010;1:136.

129. Jaworski T, Lechat B, Demedts D, Gielis L, Devijver H, Borghgraef $\mathrm{P}$, et al. Dendritic degeneration, neurovascular defects, and inflammation precede neuronal loss in a mouse model for tau-mediated neurodegeneration. Am J Pathol 2011;179:2001-2015.

130. Nilson AN, English KC, Gerson JE, Barton Whittle T, Nicolas Crain C, Xue J, et al. Tau oligomers associate with inflammation in the brain and retina of tauopathy mice and in neurodegenerative diseases. J Alzheimers Dis 2017;55:1083-1099.

131. Lu Y, Li Z, Zhang X, Ming B, Jia J, Wang $R$, et al. Retinal nerve fiber layer structure abnormalities in early Alzheimer's disease: evidence in optical coherence tomography. Neurosci Lett 2010;480:69-72.

132. Ho W-L, Leung Y, Tsang AW-T, So K-F, Chiu K, Chang RC$C$. Tauopathy in the retina and optic nerve: does it shadow pathological changes in the brain? Mol Vis 2012;18:27002710.

133. Colligris P, Perez de Lara MJ, Colligris B, Pintor J. Ocular manifestations of alzheimer's and other neurodegenerative diseases: the prospect of the eye as a tool for the early diagnosis of Alzheimer's disease. J Ophthalmol 2018;2018:8538573.

134. Berisha F, Feke GT, Trempe CL, McMeel JW, Schepens CL. Retinal abnormalities in early Alzheimer's disease. Invest Ophthalmol Vis Sci 2007;48:2285-2289.

135. Sadun AA, Bassi CJ. Optic nerve damage in Alzheimer's disease. Ophthalmology 1990;97:9-17.

136. Guo L, Duggan J, Cordeiro MF. Alzheimer's disease and retinal neurodegeneration. Curr Alzheimer Res 2010;7:314.

137. Danesh-Meyer HV, Birch H, Ku JY, Carroll S, Gamble G. Reduction of optic nerve fibers in patients with Alzheimer disease identified by laser imaging. Neurology 2006;67:1852-1854.

138. Iseri PK, Altinas O, Tokay T, Yuksel N. Relationship between cognitive impairment and retinal morphological and visual functional abnormalities in Alzheimer disease. J Neuroophthalmol 2006;26:18-24.

139. Frost S, Guymer R, Zaw Aung K, Lance Macaulay S, Sohrabi HR, Bourgeat P, et al. Alzheimer's disease and the early signs of age-related macular degeneration. Curr Alzheimer Res 2016;13:1259-1266.

140. Koronyo-Hamaoui M, Koronyo Y, Ljubimov AV, Miller CA, Ko MK, Black KL, et al. Identification of amyloid plaques in retinas from Alzheimer's patients and noninvasive in vivo optical imaging of retinal plaques in a mouse model. Neuroimage 2011;54:S204-S217.

141. Loeffler KU, Edward DP, Tso MO. Tau-2 immunoreactivity of corpora amylacea in the human retina and optic nerve. Invest Ophthalmol Vis Sci 1993;34:2600-2603.

142. Loffler KU, Edward DP, Tso MO. Immunoreactivity against tau, amyloid precursor protein, and beta-amyloid in the human retina. Invest Ophthalmol Vis Sci 1995;36:24-31.

143. Flaxman SR, Bourne RR, Resnikoff S, Ackland P, Braithwaite T, Cicinelli MV, et al. Global causes of blindness and distance vision impairment 1990-2020: a systematic review and meta-analysis. Lancet Glob Health 2017;5:e1221-e1234. 
144. Luthert PJ. Pathogenesis of age-related macular degeneration. Diagn Histopathol 2011;17:10-16.

145. Leger F, Fernagut PO, Canron MH, Leoni S, Vital C, Tison $\mathrm{F}$, et al. Protein aggregation in the aging retina. $J$ Neuropathol Exp Neurol 2011;70:63-68.

146. Wostyn P, Audenaert K, De Deyn PP. Alzheimer's disease and glaucoma: is there a causal relationship? $\mathrm{Br} J$ Ophthalmol 2009;93:1557-1559.

147. Tseng $\mathrm{H}$, Kasmala L, Proia A, McKinnon S. Expression of protein markers of Alzheimer's disease in human glaucoma eyes. Invest Ophthalmo/ Vis Sci 2007;48:32693269.

148. Chiasseu M, Cueva Vargas JL, Destroismaisons L, Vande Velde C, Leclerc N, Di Polo A. Tau accumulation, altered phosphorylation, and missorting promote neurodegeneration in glaucoma. J Neurosci 2016;36:5785-5798.

149. Oka T, Tamada Y, Nakajima E, Shearer TR, Azuma M. Presence of calpain-induced proteolysis in retinal degeneration and dysfunction in a rat model of acute ocular hypertension. J Neurosci Res 2006;83:1342-1351.

150. Branca D. Calpain-related diseases. Biochem Biophys Res Commun 2004;322:1098-1104.

151. Yoneda S, Hara H, Hirata A, Fukushima M, Inomata $\mathrm{Y}$, Tanihara $\mathrm{H}$. Vitreous fluid levels of $\beta$-amyloid (1-42) and tau in patients with retinal diseases. Jpn J Ophthalmol 2005;49:106-108.

152. Goedert M, Jakes R, Vanmechelen E. Monoclonal antibody AT8 recognises tau protein phosphorylated at both serine 202 and threonine 205. Neurosci Lett 1995;189:167-169.

153. Gupta N, Fong J, Ang LC, Yucel YH. Retinal tau pathology in human glaucomas. Can J Ophthalmol 2008;43:53-60.

154. Liu B, Rasool S, Yang Z, Glabe CG, Schreiber SS, Ge $J$, et al. Amyloid-peptide vaccinations reduce $\beta$-amyloid plaques but exacerbate vascular deposition and inflammation in the retina of Alzheimer's transgenic mice. Am J Pathol 2009;175:2099-2110.

155. Linsenmeier RA, Padnick-Silver L. Metabolic dependence of photoreceptors on the choroid in the normal and detached retina. Invest Ophthalmol Vis Sci 2000;41:31173123.

156. Calaza KC, Kam JH, Hogg C, Jeffery G. Mitochondrial decline precedes phenotype development in the complement factor $\mathrm{H}$ mouse model of retinal degeneration but can be corrected by near infrared light. Neurobiol Aging 2015;36:2869-2876.

157. Nakayama T, Goshima Y, Misu Y, Kato T. Role of Cdk5 and Tau phosphorylation in heterotrimeric $\mathrm{G}$ protein-mediated retinal growth cone collapse. J Neurobiol 1999;41:326339.

158. Allen B, Ingram E, Takao M, Smith MJ, Jakes R, Virdee K, et al. Abundant tau filaments and nonapoptotic neurodegeneration in transgenic mice expressing human P301S tau protein. J Neurosci 2002;22:9340-9351.

159. Gasparini L, Crowther RA, Martin KR, Berg N, Coleman M, Goedert $M$, et al. Tau inclusions in retinal ganglion cells of human P301S tau transgenic mice: effects on axonal viability. Neurobiol Aging 2011;32:419-433.

160. Mazzaro N, Barini E, Spillantini MG, Goedert M, Medini P, Gasparini L. Tau-Driven neuronal and neurotrophic dysfunction in a mouse model of early tauopathy. $J$ Neurosci 2016;36:2086-2100.
161. Bull ND, Guidi A, Goedert M, Martin KR, Spillantini MG. Reduced axonal transport and increased excitotoxic retinal ganglion cell degeneration in mice transgenic for human mutant P301S tau. PLoS One 2012;7:e34724.

162. Spires TL, Hyman BT. Transgenic models of Alzheimer's disease: learning from animals. NeuroRx 2005;2:423-437.

163. Ho WL, Leung Y, Cheng SS, Lok CK, Ho YS, Baum L, et al. Investigating degeneration of the retina in young and aged tau P301L mice. Life Sci 2015;124:16-23.

164. Schroer TA. Dynactin. Annu Rev Cell Dev Biol 2004;20:759-779.

165. Stamer K, Vogel R, Thies E, Mandelkow E, Mandelkow EM. Tau blocks traffic of organelles, neurofilaments, and APP vesicles in neurons and enhances oxidative stress. $J$ Cell Biol 2002;156:1051-1063.

166. Cingolani C, Rogers B, Lu L, Kachi S, Shen J, Campochiaro PA. Retinal degeneration from oxidative damage. Free Radic Biol Med 2006;40:660-669.

167. Tanito M, Masutani H, Nakamura H, Oka S-i, Ohira A, Yodoi J. Attenuation of retinal photooxidative damage in thioredoxin transgenic mice. Neurosci Lett 2002;326:142146.

168. Léveillard T, Mohand-Saïd S, Lorentz O, Hicks D, Fintz AC, Clérin E, et al. Identification and characterization of rodderived cone viability factor. Nat Genet 2004;36:755.

169. Sahel J-A. Saving cone cells in hereditary rod diseases: a possible role for rod-derived cone viability factor (RdCVF) therapy. Retina 2005;25:S38-S39.

170. Leveillard T, Sahel JA. Rod-derived cone viability factor for treating blinding diseases: from clinic to redox signaling. Sci Transl Med 2010;2:26ps16.

171. Fridlich R, Delalande F, Jaillard C, Lu J, Poidevin L, Cronin $\mathrm{T}$, et al. The thioredoxin-like protein rod-derived cone viability factor (RdCVFL) interacts with TAU and inhibits its phosphorylation in the retina. Mol Cell Proteomics 2009;8:1206-1218.

172. Byrne LC, Dalkara D, Luna G, Fisher SK, Clérin E, Sahel JA, et al. Viral-mediated RdCVF and RdCVFL expression protects cone and rod photoreceptors in retinal degeneration. J Clin Invest 2015;125:105-116.

173. Hosokawa M, Arai T, Masuda-Suzukake M, Nonaka T, Yamashita M, Akiyama $\mathrm{H}$, et al. Methylene blue reduced abnormal tau accumulation in P301L tau transgenic mice. PLOS ONE 2012;7:e52389.

174. Min S-W, Chen X, Tracy TE, Li Y, Zhou Y, Wang C, et al. Critical role of acetylation in tau-mediated neurodegeneration and cognitive deficits. Nat Med 2015;21:1154-1162.

175. Myeku N, Clelland CL, Emrani S, Kukushkin NV, Yu WH, Goldberg AL, et al. Tau-driven 26S proteasome impairment and cognitive dysfunction can be prevented early in disease by activating cAMP-PKA signaling. Nat Med 2016;22:46-53.

176. Yanamandra K, Kfoury N, Jiang H, Mahan TE, Ma S, Maloney SE, et al. Anti-tau antibodies that block tau aggregate seeding in vitro markedly decrease pathology and improve cognition in vivo. Neuron 2013;80:402-414.

177. Castillo-Carranza DL, Sengupta U, Guerrero-Munoz MJ, Lasagna-Reeves CA, Gerson JE, Singh G, et al. Passive immunization with Tau oligomer monoclonal anti- 
body reverses tauopathy phenotypes without affecting hyperphosphorylated neurofibrillary tangles. J Neurosci 2014;34:4260-4272.

178. Bi M, Ittner A, Ke YD, Götz J, Ittner LM. Tau-targeted immunization impedes progression of neurofibrillary histopathology in aged P301L tau transgenic mice. PLOS ONE 2011;6:e26860.

179. Boimel M, Grigoriadis N, Lourbopoulos A, Haber E, Abramsky O, Rosenmann H. Efficacy and safety of immunization with phosphorylated tau against neurofibrillary tangles in mice. Exp Neurol 2010;224:472-485.

180. Ittner A, Bertz J, Suh LS, Stevens CH, Götz J, Ittner LM. Tau-targeting passive immunization modulates aspects of pathology in tau transgenic mice. J Neurochem 2015;132:135-145.

181. Brunden $K R$, Ballatore $C$, Crowe $A$, Smith $A B$, Lee VM-Y, Trojanowski JQ. Tau-directed drug discovery for Alzheimer's disease and related tauopathies: a focus on tau assembly inhibitors. Exp Neurol 2010;223:304-310.

182. Mohamed T, Hoang T, Jelokhani-Niaraki M, Rao PP. Tau-derived-hexapeptide 306VQIVYK311 aggregation inhibitors: nitrocatechol moiety as a pharmacophore in drug design. ACS Chem Neurosci 2013;4:1559-1570.

183. Mohamed T, PN Rao P. Alzheimer's disease: emerging trends in small molecule therapies. Curr Med Chem 2011;18:4299-4320.

184. Dammers C, Yolcu D, Kukuk L, Willbold D, Pickhardt M, Mandelkow E, et al. Selection and characterization of tau binding $D$-enantiomeric peptides with potential for therapy of Alzheimer disease. PLOS ONE 2016;11:e0167432.
185. Matsuoka Y, Jouroukhin Y, Gray AJ, Ma L, Hirata-Fukae $\mathrm{C}$, Li H-F, et al. A neuronal microtubule-interacting agent, NAPVSIPQ, reduces tau pathology and enhances cognitive function in a mouse model of Alzheimer's disease. $J$ Pharmacol Exp Ther 2008;325:146-153.

186. Ivashko-Pachima Y, Maor-Nof M, Gozes I. NAP (davunetide) preferential interaction with dynamic 3-repeat Tau explains differential protection in selected tauopathies. PLOS ONE 2019;14:e0213666.

187. Eschmann NA, Do TD, LaPointe NE, Shea J-E, Feinstein SC, Bowers MT, et al. Tau aggregation propensity engrained in its solution state. J Phys Chem $B$ 2015;119:14421-14432.

188. Schafer KN, Cisek K, Huseby CJ, Chang E, Kuret J. Structural determinants of tau aggregation inhibitor potency. $J$ Biol Chem 2013;288:32599-32611.

189. Levine ZA, Larini L, LaPointe NE, Feinstein SC, Shea JE. Regulation and aggregation of intrinsically disordered peptides. Proc Natl Acad Sci 2015;112:2758-2763.

190. Nadimidla K, Ismail T, Kanapathipillai M. Tau peptides and tau mutant protein aggregation inhibition by cationic polyethyleneimine and polyarginine. Biopolymers 2017;107:e23024.

191. DeVos SL, Goncharoff DK, Chen G, Kebodeaux CS, Yamada K, Stewart FR, et al. Antisense reduction of tau in adult mice protects against seizures. J Neurosci 2013;33:12887-12897.

192. Khosravi Z, Khalili MAN, Moradi S, Sajedi RH, Zeinoddini M. The molecular chaperone artemin efficiently blocks fibrillization of TAU protein in vitro. Cell J 2018;19:569-577. 